\section{To contribute to health, we need to understand who we are treating}

\author{
David Hughes
}

"Travel is fatal to prejudice, bigotry, and narrow-mindedness," wrote Mark Twain. The more one travels, the more one realises that all human beings crave the same essential ingredients in life: safety, prosperity, the affection of others and good health. As healthcare professionals, we have the ability and opportunity to contribute to the good health of others. To make this contribution meaningful, however, we first need to understand the definitions of 'health' and 'normal'.

Furthermore, to effectively intervene to improve the health of another, we need to understand how the particular health issue is impacting on the functional capacity of that individual. Two of my patients illustrated this point. The first was an elite level cyclist who had fallen off her bicycle a week prior, suffering a deep and long soft tissue laceration just below the knee, requiring extensive suturing and leaving a very impressive wound. The second athlete was a para-canoe athlete with a T6 level spinal lesion with painful blisters on both thumbs. The blisters had been caused by canoeing but were severe enough to now be causing difficulty with wheelchair mobility. At first glance, the blisters might have seemed relatively trivial compared to the cyclist's leg wound. In terms of the potential threat to functional capacity; however, the blisters were a far more significant injury.

\section{THE CONCEPT OF 'HEALTH' IS MULTIDIMENSIONAL}

In this ACSP issue, Jennifer Baldwin and colleagues (see page 1225 and 1226) discuss the concept of defining 'health'. What may be a significant health issue to one individual may be quite insignificant to another. The concept of 'health' is relative and determined by a range of factors, including specific character traits, sociocultural factors and particular physical factors, which all have the potential to challenge the individual. Our understanding of 'health' must take into account the human experience. Baldwin and colleagues also make the point that it is difficult to judge illhealth unless one knows what is 'normal'

Correspondence to Dr David Hughes, Australian Institute of Sport, Australian Sports Commission, Leverrier Street, Bruce, ACT 2617, Australia; david.hughes@ausport.gov.au

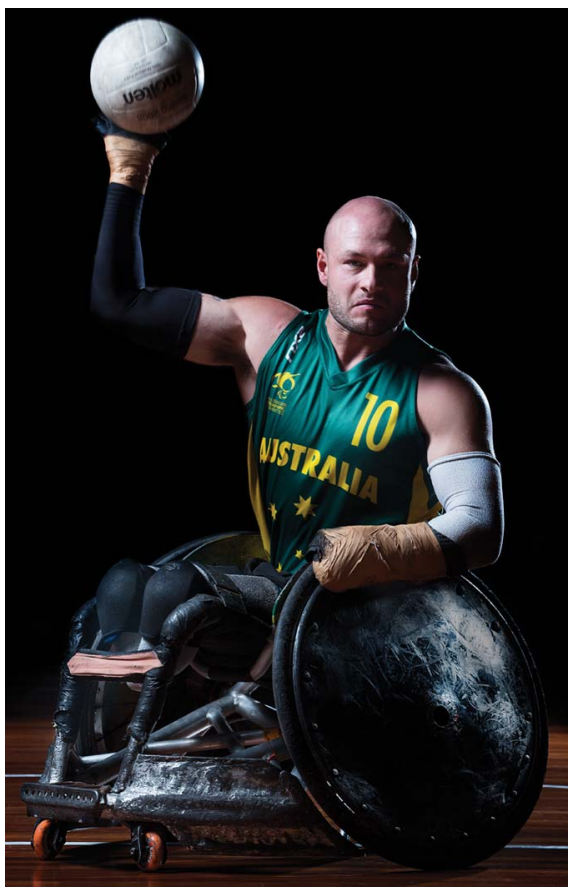

Figure 1 Clinicians need to understand that 'health' is a relative concept

for individuals with reference to their age, gender and social circumstances. Without an understanding of 'normal', there is an inherent danger of overmedicalisation.

\section{AUTHORITATIVE GUIDE FOR SPINAL CORD INJURED PATIENTS}

Spinal cord injuries (SCIs) are, unfortunately, not uncommon. One of the unique health challenges facing individuals with SCI is bladder dysfunction, requiring permanent or intermittent catheterisation and the increased risk of urinary tract infection (UTI). Despite the fact that SCI affects over 12000 Australians, there has until now been no authoritative guide to indicate the most appropriate management of UTI in athletes with SCIs. The Australian Institute of Sport (AIS) and the Australian Paralympic Committee (APC) have published a consensus statement on UTI in athletes with SCIs (see page 1236). One of the dangers for these athletes is potential overtreatment by well-meaning practitioners who do not understand what 'normal' is in this cohort of athletes.

Hand-rim wheelchair propulsion presents a challenging but essential motor task for manual wheelchair users, especially those who may already be physically deconditioned (figure 1). Little is known, however, about the effect of exercise training on manual wheelchair propulsion capacity. Joanna Diong and Claire Boswell-Ruys (see page 1284) conducted a PEDro synthesis, revealing a paucity of quality research in this area. Current evidence suggests that aerobic exercise training, strength training and mixed training improve endurance and enhance wheelchair propulsion capacity. Well-designed prospective research studies are required to better understand the factors affecting wheelchair propulsion capacity. However, the studies identified were mostly of poor quality, with a median PEDro score of 2 where 10 is the maximum on the 11-item scale. ${ }^{1}$ I urge those readers not familiar with PEDro to try the site for ready evidence based management guides (http:// www.pedro.org.au/).

\section{EVIDENCE AND PRACTICE-WHEN TWO WORLDS DIVIDE}

We like to think that the practice of medicine is increasingly aligned with reliable evidence from appropriately designed research. A systematic review and meta-analysis by Thorlund et $a l^{2}$ indicates otherwise. Despite clear and growing evidence that arthroscopic surgery delivers no benefit versus placebo in the degenerative knee, arthroscopic knee surgery is increasingly being used to treat middle-aged and older patients having persistent knee pain. Please also see Professor Andy Carr's linked editorial. ${ }^{3}$ In his editorial devoted to this topic, ACSP's John Orchard explores some of the perverse incentives that may explain the stark contrast between the evidence and practice of arthroscopic knee surgery (see page 1229).

There have been many technological advances in sport over the past couple of decades, including 'improvements' in playing surfaces and footwear. What appears to be improved technology, however, does not necessarily equate to improved outcome for athletes. Stepping and pivoting is common in football codes. These athletic manoeuvres are associated with lower limb injuries. ${ }^{4}$ A systematic review of studies investigating the relationship between rotational traction and injury rates concluded that higher levels of rotational traction at the foot-surface interface were associated with a 2.5 -fold increase in injury risk in American footballers (see page 1245).

Peter Brukner provides an excellent overview of what we know and don't know about hamstring injuries (see page 1241). Hamstring injury, surely one of the most researched and talked about injuries in 
sports medicine, continues to confound sports medicine professionals around the globe. While there is broad agreement on some issues (eg, worse prognosis with slow stretch, intratendinous and origin-zone injuries), there is much debate and conflicting research on risk factors for hamstring injury, the role of MRI in predicting return to play and the benefit or otherwise of injection interventions. It seems that hamstrings will keep $\mathrm{PhD}$ students gainfully occupied for some time yet. Underscoring both the challenges and consistent progress, UK sports physician Pollock et $a l^{5}$ described the British Athletics Muscle Injury Classification system last year. While scanning the 'online first' section of BJSM, I saw the authors retrospectively applied the grading system to 65 hamstring injuries in 44 athletes, demonstrating correlation between grade of injury and time to return to full training, with grade 3 and ' $\mathrm{C}$ ' injuries taking significantly longer and grade 0 injuries taking less time to return to full training. ${ }^{6}$ I look forward to BASEM's publication of this journal (issue 21, November).

\section{A SIMPLE DOSE OF EXERCISE DECREASES MEDICALISATION}

High-intensity intermittent training (HIIT) is becoming an increasingly popular and advocated mode of physical activity, with several studies supporting its use to ameliorate the effects of metabolic syndrome. Part of the popularity of HIIT stems from its time-efficient format for a populace that perceives itself as increasingly time-poor. Costigan and co-workers systematically reviewed HIIT in adolescents, examining health-related fitness outcomes (see page 1253). This study indicates that, among adolescents, as among other population groups, HIIT is a feasible and time efficient means of improving cardiorespiratory fitness and body composition.

Pain from patellar tendinopathy is often recalcitrant and poses a therapeutic challenge for sports medicine professionals. The concept of a non-invasive, cost-free means of reducing patella tendon pain is seductive. Newly minted PhD and physiotherapist Ebonie Rio and co-workers (see page 1277) investigated the effects of isometric and isotonic quadriceps contraction on patellar tendinopathy pain. The isometric exercise caused immediate reduction in pain and this effect was sustained at $45 \mathrm{~min}$. The clinical implications are that isometric exercise using $70 \%$ of maximal voluntary contraction may be a useful protocol prior to activity to reduce pain without inducing muscle fatigue. It may also be useful in nearly all stages of rehabilitation to inhibit pain and allow optimal gains from subsequent rehabilitation exercises.

While physical inactivity continues to contribute to the ill-health of large portions of the world's population, many barriers to improving physical activity levels yet remain. Marcia Franco conducted a systematic review on the attitudes of individuals over the age of 60 years to physical activity (see page 1268). While many appreciated the potential health benefits of remaining physically active, they were discouraged from participating in physical activity by a range of barriers including social awkwardness, competing priorities, fears of falling, or other perceived risks of physical activity. The study indicates that individuals over the age of 60 years would benefit from education around the favourable risk-reward ratio of maintaining a physically active lifestyle.

As clinicians, we aspire and desire to improve the health of our patients and our communities. To do this effectively, we need to understand that 'health' is a relative concept. We need to be armed with normative data relevant to the patient sitting in front of us. We need access to high quality published research to inform treatment choices. Most of all, however, we need to understand who the patient is, what their deepest fears and greatest aspirations are, and ensure that any advice we give delivers 'health' that is relevant and valuable to that individual.

And as we go to press I can give you the first notice of the 2016 ACSP conference. Keep 13-15 February to be at Queensland's Gold Coast. Keynote speakers include Roald Bahr (Norway), Steven Blair, Lynn Snyder-Mackler and James MacDonald (all from USA).

Competing interests None declared.

Provenance and peer review Commissioned; internally peer reviewed.

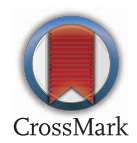

To cite Hughes D. Br J Sports Med 2015;49:12211222.

Accepted 14 August 2015

Br J Sports Med 2015;49:1221-1222.

doi:10.1136/bjsports-2015-095379

\section{REFERENCES}

1 Kamper SJ, Moseley AM, Herbert RD, et al. 15 Years of tracking physiotherapy evidence on PEDro, where are we now? Br J Sports Med 2015;49: 907-9.

2 Thorlund JB, Juhl CB, Roos EM, et al. Arthroscopic surgery for degenerative knee: systematic review and meta-analysis of benefits and harms. BMJ 2015;350: h2747.

3 Carr A. Arthroscopic surgery for degenerative knee. BMJ 2015;350:h2983.

4 Hübscher M, Refshauge KM. Neuromuscular training strategies for preventing lower limb injuries: what's new and what are the practical limitations of what we already know? Br J Sports Med 2013;47:939-40.

5 Pollock N, James SL, Lee JC, et al. British athletics muscle injury classification: a new grading system. $\mathrm{Br} J$ Sports Med 2014;48:1347-51.

6 Pollock N, Patel A, Chakraverty J, et al. Time to return to full training is delayed and recurrence rate is higher in intratendinous (' $c$ ') acute hamstring injury in elite track and field athletes: clinical application of the British Athletics Muscle Injury Classification. $\mathrm{Br} J$ Sports Med Published Online First: 17 July 2015 doi:10.1136/bjsports-2015-094657 